\title{
ESTIMATION AND PLANNING TOOL FOR INDUSTRIAL CONSTRUCTION SCAFFOLDING
}

*C. Kumar, S. M. AbouRizk, and Y. Mohamed

Department of Civil and Environmental Engineering

University of Alberta

Edmonton, AB, Canada, T6G 2R3

(*Corresponding author: chandan1@ualberta.ca)

H. Taghaddos, and U. Hermann

PCL Industrial Management Inc.

Edmonton, AB, Canada, T6E 3P4 


\title{
ESTIMATION AND PLANNING TOOL FOR INDUSTRIAL CONSTRUCTION SCAFFOLDING
}

\begin{abstract}
Scaffolds are temporary structures built to facilitate construction activities on site. A considerable amount of resources are allocated to scaffolding on industrial projects. Variability in geometrical features and space accessibility of structures on industrial projects, in addition to involvement of different trades that share the use of scaffolds, requires an extensive understanding of scaffolding requirements. Hence, it's important to plan and estimate scaffolding man-hour requirements for the different construction areas on an industrial site. Contributing factors involved in such estimates include the list of trades that work in a construction area, trade working hours, volume of work, geometry of equipment erected, etc. A simulation template for predicting scaffold erection man-hour values for individual construction areas in an industrial project was developed in Simphony 4.0. The template is based on mapping the geometry of equipment and other factors to man-hours of scaffold work. The template facilitates the use of distributions as inputs and produces a range estimate of scaffold man-hours. The mapping is based on a linear regression model derived from existing project data from PCL Industrial Management Inc. The template is being further developed to incorporate the ability to predict scaffold erection schedule and material requirements based on construction work areas or equipment lists of an industrial construction project.
\end{abstract}

\section{KEYWORDS}

Scaffolding, Industrial Construction, Estimation

\section{INTRODUCTION}

Scaffolds are temporary structures built to facilitate the work of labourers, mostly at higher-thanground-level elevations. Scaffolds are an integral part of any high-rise construction operation, be it in the field of residential or industrial construction. While the scaffolding process is often considered to be of lesser importance within the overall project, it accounts for a significant amount of project cost and labourhours. Understanding scaffolding construction requirements necessitates extensive knowledge of the geometrical features and space accessibility of structures on industrial projects, in addition to involvement of different trades that share the scaffolds. Contributing factors involved in scaffold estimates include the list of trades that work in a construction area, trade working hours, volume of work, elevation at which the scaffold is to be constructed, time of the year of construction, skill level of the workers, ease and type of material availability, etc. However, not all factors share the same level of importance in the estimating process.

\section{LITERATURE REVIEW}

Scaffold construction methodologies have remained constant for many years; variations are often limited to small alterations in construction methods or materials used. However, understanding the system itself is not an easy task as it involves a wide range of influencing factors. Planning scaffolding is equally as important as planning permanent construction for a project, particularly to have a clear idea of required resources and to avoid work space conflicts, which can lead to decreased productivity (Guo, 2002). Elbeltagi et al. (2001) discuss site layout planning with scaffolding materials and facilities as an integral part of such an analysis. Feuffel et al. (2009) talk about the Work Face Planning model developed by 
COAA (Construction Owners Association of Alberta), and the need to assign responsibility for coordination and planning of scaffolding. Hyunjoo et al. (2011) discuss the planning mechanism for temporary structures, primarily scaffolds, for building construction using Building Information Modeling (BIM); however, building construction is comparatively less situation dependent and more symmetrical than industrial construction, but useful information can be gathered from Hyunjoo et al.(2011)'s research and can be made relevant to the present research. Use of a particular kind of scaffolding system depends on the availability of labour and materials, which varies in different places. Kim et al. (2007) present a heuristic approach to predict the type of scaffolding system for a particular kind of construction work.

Industrial construction has an ever-changing nature, and scenarios change on a day-to-day basis; hence, accurate prediction of scaffold needs before the start of a project is difficult. Based on discussions with the Scaffold Superintendent in the PCL Modular Yard, Project Manager, Civil Superintendent (30 years' experience) and Construction Manager in Industrial Construction Section over the course of my research, it can be concluded that involving the Construction Engineer and Scaffold Superintendent in the estimation and planning process at the bidding stage optimizes the process. Fedock (1999) talks about the importance of involving construction engineers in the design of temporary structures. This practice enables cost savings and enhances design of innovative systems. Bajaj et al. (1999) compare the cost in using different systems. Literature involving actual estimation of industrial construction scaffolding is extremely limited and mostly constrained to handbooks; however, most companies have their own estimating procedures. The safety perspective of scaffolding is also important, as scaffolding is, in most cases, a temporary structure, and hence, construction rules are often not followed stringently. Halperin et. al (2004) explain scaffold safety with a case study, and describe some flaws that generally exist in scaffold erection on site. Research related to construction safety on site also mentions scaffolding as an important component (Sawacha et al., 1999).

The construction process of scaffolds in industrial projects has to adhere to many guidelines, which can vary in different countries; however, the broad outlook of safe practices remains the same. In USA and Canada, steel tubular scaffolding or some minor modified form of it is used in most cases, and is normally governed by rules and specifications indicated by organizations like OSHA (Occupational Safety and Health Administration) and CSA (Canadian Standards Association). In Alberta, Canada in particular, scaffolding is governed by Canadian Standards as well as OH\&S (Occupational Health \& Safety) Alberta guidelines. Most companies also maintain handbooks generated based on existing standards as well as their own working methods.

\section{INDUSTRIAL CONSTRUCTION SCAFFOLDING}

Industrial construction scaffolding operates mostly on an as-needed basis. Planning scaffolding beforehand for projects like petrochemical plants, refineries, etc. is very difficult due to uncertainties in the design specifications of relevant modules, vessels and structures at the start of the project. The level of detail of scaffolding requirements at the start of a project or during the estimation phase is vague, and hence, concrete methods to predict scaffolding are difficult to develop. However, a high-level estimation process can be generated at the initial stage of the project in absence of minute details, by meticulously analyzing existing industry data from past projects and concluding deterministic relationships between scaffold erection man-hours with direct hours of trade work and other relevant affecting factors.

In discussing estimation related to construction processes, the level of detail, available data resources and where the estimate fits in the timeline of the project regulates the accuracy and precision of 
the estimation process. Based on this, a scaffolding estimate can be divided into two parts, MACRO and MICRO estimate. A MACRO estimate is a high-level estimate, predominantly conducted at the bidding stage. It is constrained by a lack of sufficient available information. Based on discussion with Senior Estimator and Project Manager (individual experience of over 20 years) at PCL Industrial; it was found that most companies are dependent on estimating scaffold as a percentage of direct work. A MICRO estimate would add a more detailed level. It would help estimators pinpoint scaffold requirements at the Work Area or Work Package level of detail, even as detailed as construction of one vessel/module, etc. Development of a mechanism to arrive at this level of detail would require looking at the scaffolding requirements as a function of the geometry of the original structure. Basic features like length, breadth, height and weight of the structure to be erected/constructed, elevation of construction, the type of area in which the structure falls, and so on would impact the scaffolding requirements. The present research to accommodate a more detailed level of estimation is ongoing. Figure 1 shows the use of scaffolding in an industrial construction site.
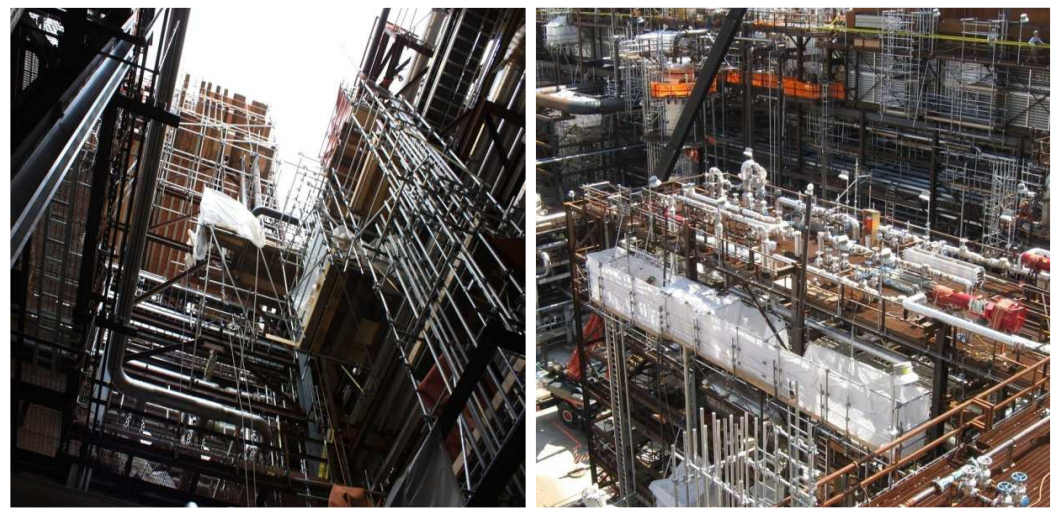

Figure 1 - Use of scaffolding in industrial construction site

\section{SCAFFOLD PROCESS MODEL}

Based on discussions of the working process with the Scaffolding Coordinator in a leading industrial construction contractor, a business process model was developed. A simplified version of the model is shown in Figure 2.

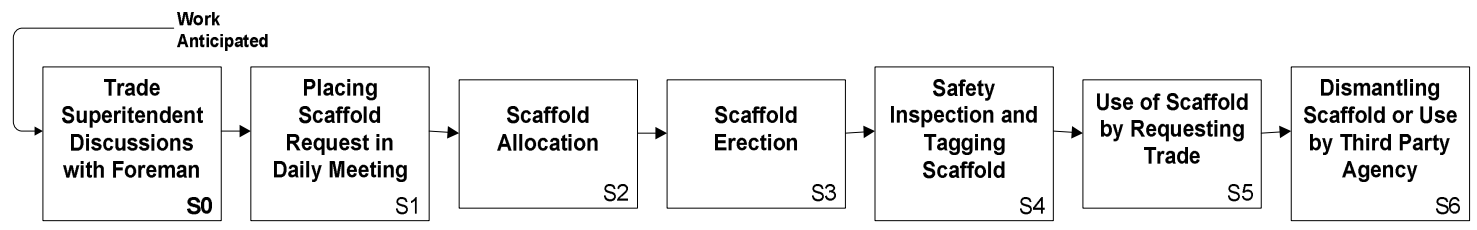

Figure 2 - Process flow model for scaffold erection

A MICRO model of estimation would come into play in most cases in the Scaffold Allocation and Scaffold Erection phases of the process. The Scaffold Superintendent, using the estimation tool, would be able to determine the labour crew size and duration of work for the construction of one particular scaffold. However the same tool can be used before the start of the project to analyze the requirements of the whole project. Development of such a model is still in progress, as it involves a greater level of detail and 
analytical technique. A very effective way of arriving at the same conclusion is use of Data Mining techniques on available company data sets. Many discussions have been held with professionals at PCL (e.g. Senior Estimator, Construction Manager in Industrial Construction) involved in different phases of estimation or construction to try to identify the contributing factors that most affect scaffolding requirements. This research has begun, in collaboration with PCL Industrial Management Inc., and is still in progress.

\section{ESTIMATION TECHNIQUE AND TOOL}

\section{Data Available}

The data available was a Scaffold Database, which was maintained during the course of one of PCL's earlier projects. The database constitutes more than 15,000 entries. The list of the columns in the database includes ScaffoldID, Comment, Date Requested, Date Required, Requested by Trade, Area Location, Elevation, Priority, Superintendent, Foreman to build, Actual Volume, Units, Cost Code, Erection Mhrs, Mhrs Dismantle, Completion Date, Status, Reason for Dismantle, Date Dismantled and IWP. The database keeps track of scaffold requirements for equipment at the major construction areas of the project. However, considerable data cleaning is required as the nomenclature maintained to track works in the database is not consistent.

\section{Data Organization and Management}

Different input sets are extracted from the database to build models at either the MACRO or MICRO level of analysis. The estimation tool to be built will feature estimation at different levels of analysis, as explained before. For a higher level analysis or MACRO level, the major areas in the database (18 in total) are grouped together at trade ( 8 trades) level of analysis making an input set of 144 input entries (Wu, 2013). While the working principles would be the same for the estimating tool in MICRO or detailed estimation (described in this paper below), the type and amount of inputs would differ with MACRO estimation. The idea is to extract scaffold information for individual vessels, modules, equipment, etc. from the database entries and relate them to the geometrical parameters of the respective equipment to reduce the dependency on trade hours which are not always consistent.

\section{Concept}

Simulation is an effective technique of planning processes in construction. "Simphony is a Microsoft Windows based computer system developed with the objective of providing a standard, consistent and intelligent environment for both the development as well as the utilization of construction SPS (Special Purpose Simulation) tools" (Hajjar, 1999). The use of such a tool enables using Stochastic Values as inputs for the model and collection of relevant statistics for outputs desired. The goal is development of an estimating tool in Simphony that can be used both at MICRO and MACRO levels of estimating. The tool in development is based on PCL data, and hence, customized to their use. That being said, the working principle of the tool remains generic and minor changes can be made for inputs if similar data is obtained from another company in the industry.

Numerical inputs in the estimating tool can be fed in the form of all major probabilistic distributions. This allows the user to get a range estimate in the output of scaffold man-hours, which 
represents a closer association with real-life scenarios and takes into account the uncertainty in industrial construction.

\section{Elements}

Table 1 - Elements of the template and their symbolic representations

$\begin{array}{ll}\begin{array}{l}\text { Name of } \\ \text { Element } \\ \text { Template }\end{array} & \begin{array}{l}\text { Symbol in } \\ \text { Start }\end{array} \\ \text { Area } & \text { - Senerates an entity and starts the simulation process. } \\ \text { - Rnd } & \begin{array}{l}\text { Takes a set of inputs, maps them using relationships already fed in } \\ \text { the element to produce outputs. }\end{array}\end{array}$

\section{Inputs}

Data mining experiments are conducted on the input set extracted from the available database to predict relationships between scaffold erection man-hours and applicable input factors. For the MICRO analysis, the input factors will be properties associated with the individual pieces of equipment like vessels or modules. The columns in data mining analysis are Type of Equipment, Length, Breadth and Height of the equipment, Weight of the Equipment, Elevation of construction or erection and the Scaffold Manhours. The present research's attempt to model scaffolding man-hours as a function of physical geometry of the equipment, is a more logical and generic analysis which can be implemented in any company. Based on the initial analysis in MICRO estimation, the proposed inputs are as below.

Table 2 - Inputs in Estimating Tool

\begin{tabular}{|c|c|}
\hline Input Name & Description \\
\hline Type of Equipment & $\begin{array}{l}\text { - Vessel, Rack Module, Cable Tray Module, Valve Deck, } \\
\text { Structure, Process Equipment }\end{array}$ \\
\hline $\begin{array}{l}\text { Length, Breadth and } \\
\text { Height }\end{array}$ & - Geometry of the equipment \\
\hline Weight & - Weight of the equipment \\
\hline $\begin{array}{l}\text { Elevation of } \\
\text { Construction }\end{array}$ & $\begin{array}{l}\text { - The elevation from ground where the equipment has to } \\
\text { be erected at site }\end{array}$ \\
\hline
\end{tabular}


It is to be noted that the research to determine the relationships of these inputs to scaffold manhours of work and correlate them to other relevant outputs like amount of materials is still in progress. The decision to include these factors is based on discussions with the Civil Superintendent in PCL (30+ years of experience) and the Director of Construction, Gracom. Linear Regression technique is used as a method to compute relationships and WEKA software is used to implement linear regression. WEKA is data mining software developed in JAVA by Machine Learning Group at the University of Waikato, New Zealand.

\section{Working Principle}

An area in this estimating tool would represent a construction work area in an industrial construction site. It can be as small as a module or as big as a collection of industrial equipment.

The factors that affect the final output will be determined through data mining exercises performed using WEKA on the scaffold database. The user would be able to select the type of estimate needed: MACRO or MICRO. Different inputs are required for respective estimates. The inputs for MICRO estimation are the main concern of this research, as it is shown above in Table 2. Figure 3 shows the working principle of the simulation tool.

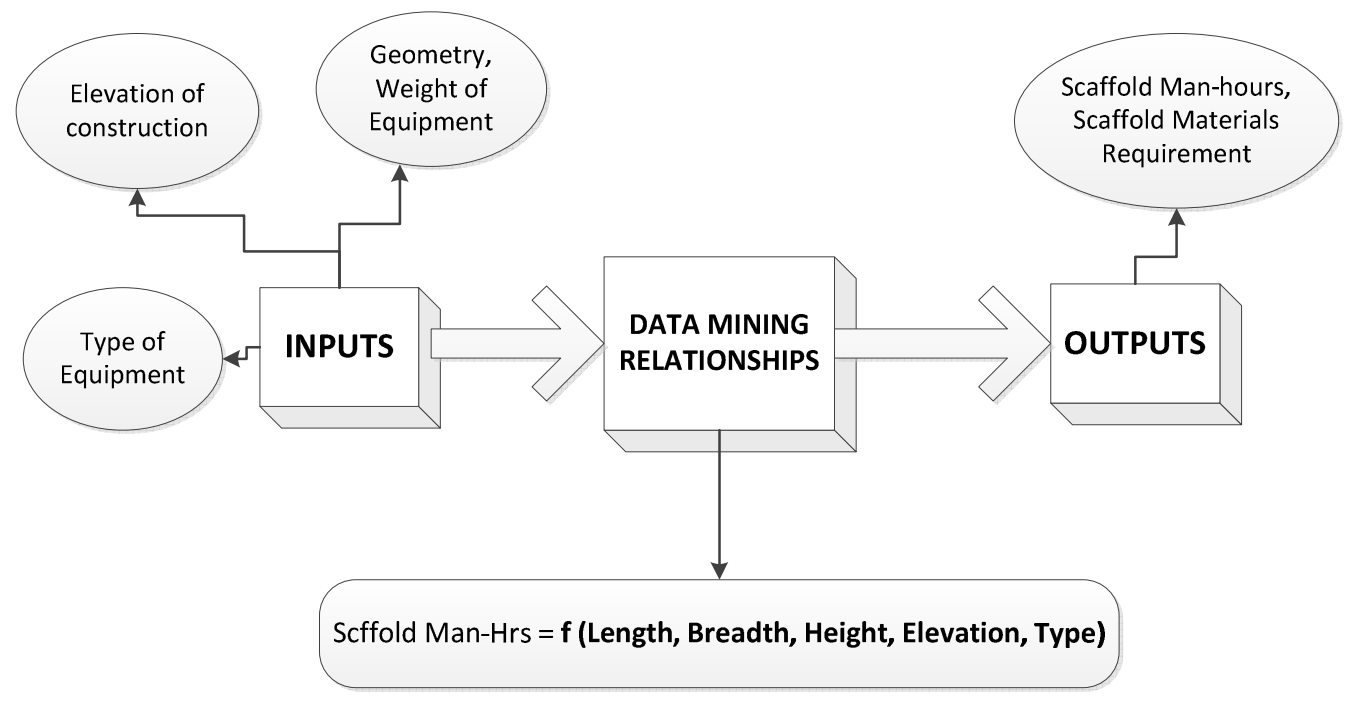

Figure 3 - Working mechanism of Special Purpose Simulation tool

\section{Outputs}

Statistics on the total scaffold man-hours for a construction area can be collected for each run of the simulation model. As described, the model takes inputs in the form of distributions, and hence, the simulation template is run for more than one run to evaluate the output as a range estimate. A sample output is shown below in Figure 4. The tool also provides statistical parameters for range estimation like mean, standard deviation, etc. The output shown is for representative purposes only and does not include actual data. 

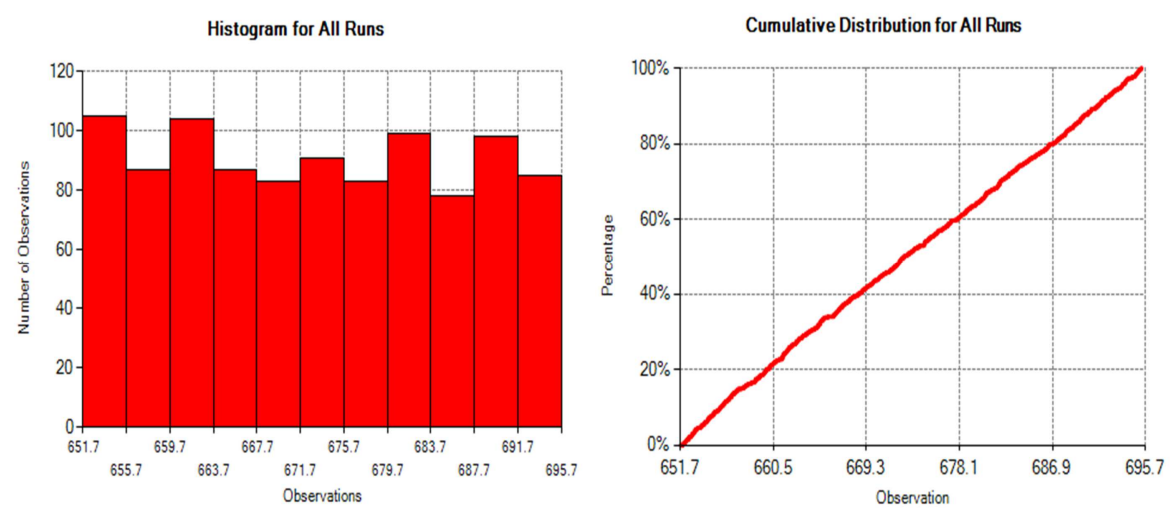

Figure 4 - Sample output

Interpretation of the output depends on what the output is used for. A 90 percentile value calculated from the output results could be used for bidding purposes or material renting. Or, it can assist in calculating the man-power requirements for the whole project or at the equipment level. While the output at its present condition is still in the raw phase, further ongoing development will improve it.

\section{FUTURE WORK}

This paper represents only a stepping stone to the possibility in this research area. Scaffolding has not been a well-researched field in construction. Present research involves formulating the functional relationships on geometric dimensions of the structure. Future work in this research would involve developing the template further to simplify inputs and the user interface. Different techniques of estimation like existing handbooks, which may become a part of the template, are presently being investigated for doing comparative studies. Scaffold type is not addressed here, and could be incorporated to further enrich the template. $3 \mathrm{D} / 2 \mathrm{D}$ plot plans of the industrial site could be integrated with the template to visually represent the necessity and amount of scaffolding required. Estimation of materials required could also be added as a component, and the possibilities of this are still under investigation. A fully-functional MICRO and MACRO estimating tool, linked with the project schedule, would assist in scheduling scaffolding for industrial construction work packages.

\section{DISCUSSIONS}

Existing literature does not deal in depth with a particular mechanism or process to properly plan and estimate scaffolding in industrial construction projects. The necessity of such a template arises from the fact that scaffolding consumes a considerable amount of resources in an industrial construction project. This research began after several industry partners associated with the Construction Research Group at the University of Alberta, Canada identified the need. They found planning and estimation of scaffolding to be a timely concern in the industry, and relevant tools and techniques to be missing from the construction industry. This paper formulates an initial plan to solve such a problem. Data mining techniques represent true characteristics of a company's performance in scaffolding work on a particular project. This method could help in identifying loose links and bottlenecks in the scenario, and relevant steps could be taken to eradicate problems. 


\section{REFERENCES}

Bajaj, D., \& Kumar, A. (1999). Cost Comparison of Scaffolding Systems for High Rise Construction. AACE International Transactions, CSC, 15.

Standards Council of Canada. (1987). CAN/CSA-S269.2-M87(R 2003) Access Scaffolding for Construction Purposes ( $2^{\text {nd }}$ ed.).

Elbeltagi, E., \& Hegazy, T. (2001). A hybrid AI-based system for site layout planning in construction. Computer-Aided Civil and Infrastructure Engineering, 16, 2, 79-93.

Fedock, D. S. (1999). The Role of Construction Engineer in the Design of Temporary Structures for Construction in the Power Generation, Process and Petrochemical Industries. American Society of Civil Engineers, Structures Congress (pp. 923-926).

Feuffel, J., \& Hanley Jr., K. (2009). Workface Planning. PCL Industrial Constructors Inc. (Sites), Excellence in Construction, PCL College of Construction.

Guo, S. (2002). Identification and resolution of work space conflicts in building construction. Journal of Construction Engineering and Management, 128, 4, 287-295.

Hajjar, D., \& Abourizk, S. (1999). Simphony: An environment for building special purpose construction simulation tools. Winter Simulation Conference (Vol. 2, pp. 998-1006).

Halperin, K.M., \& McCann, M. (2004). An evaluation of scaffold safety at construction sites. Journal of Safety Research, 35, 141-150. doi: 10.1016/j.jsr.2003.11.004

Hyunjoo, K., \& Hongseob, A. (2011). Temporary facility planning of a construction project using BIM (Building Information Modeling). International Workshop on Computing in Civil Engineering (pp. 627-634). Reston, VA: ASCE .

Kim, J., \& Fischer, M. (2007). Formalization of the features of activities and classification of temporary structures to support an automated temporary structure planning, Computing in Civil Engineering: ASCE International Workshop on Computing in Civil Engineering (pp. 338-346). ASCE.

Sawacha, E., Naoum, S., \& Fong, D. (1999). Factors affecting safety performance on construction sites. International Journal of Project Management, 17, 5, 309-315.

U.S. Department of Labor, Occupational Safety and Health Administration. (1996). Scaffolding. Construction Safety and Health Outreach Program. Retrieved from http://www.osha.gov/doc/outreachtraining/htmlfiles/scaffreg.html.

Wu, L. (2013). Internal Progress Report. Unpublished report, Department of Civil and Environmental Engineering, University of Alberta, Edmonton, AB. 